\title{
Analysing Intercultural Dialogue Through Conceptual Densities
}

\begin{abstract}
In this chapter, we exemplify our methodological approach to analysing 'densities' of interrelated concepts in European education policy documents. We scrutinize instances where many of the core concepts of intercultural dialogue appear in the documents at the same time. Four core educational themes and four longer excerpts from the selected policy documents are examined in more detail. The chosen documents deal especially with multilingualism, migration, history teaching, and lifelong learning. The analysis of the conceptual densities in the chosen excerpts indicates how the meanings of intercultural dialogue are constructed through the conceptual frameworks and co-occurrences of their core concepts in the documents, rather than through explicit definitions of the concept of intercultural dialogue itself.
\end{abstract}

Keywords Conceptual density $\bullet$ Multilingualism $\bullet$ Migration $\bullet$ History teaching • Lifelong learning

As the data excerpts in the previous chapter indicate, intercultural dialogue is discussed in European education policy documents through several conceptual variations, such as intercultural communication (CofEC 2005, 9; EP \& CofEU 2006, 15, 17; CofE 2011b, 11), intercultural or cross-cultural understanding (CofEC 2005, 8, 2013, 49, 52; EP \& CofEU 
2006, 14, 2013, 50n6), intercultural competences and skills (CofE 2008a, 2; CofEU \& EC 2015), intercultural and entrepreneurial capacities (CofEC 2008a, 3), and intercultural awareness (EP \& CofEU 2013, 58). The previous chapter also showed how intercultural dialogue is discussed in both academic literature and policy discourses through various conceptual frameworks and expressions. It is also implicitly referred to by emphasizing respect for cultural diversity, mutual understanding between individuals, and the importance of familiarizing oneself with Europe's culturally diverse features.

The most common contexts in which intercultural dialogue appears in our data include multilingualism, history teaching, and immigration. All the concepts, conceptual frameworks, and expressions used in discussing intercultural dialogue broaden its range of meanings, as these concepts, frameworks, and expressions include different semantic webs. When it is approached in our data through the contexts of linguistic diversity and multilingualism (e.g. CofEC 2008b), the idea of intercultural dialogue is framed through the themes of language learning and linguistic diversity and dialogue between cultures. However, when intercultural dialogue is connected to the semantics of religion (CofE $201 \mathrm{lb}, 2$ ), it transforms into "interfaith dialogue" and includes religious diversity and interaction. Moreover, references to intercultural skills and competences (EP \& CofEU 2006, 16; CofEC 2008b, 11) and intercultural education (CofE $2011 \mathrm{a}, 5, \mathrm{~b}, \mathrm{l}, 2)$ flesh out the educational and pedagogical contexts, as well as the importance of intercultural dialogue for the broader society.

In European education policies, therefore, intercultural dialogue is either explicitly or implicitly connected to diverse contextual frameworks, which occur with varying frequency. In order to narrow down and deepen our analysis of the overlaps and interrelatedness of the different concepts, terms, and expressions used for referring to intercultural dialogue, we have chosen to focus on four core educational themes. These themes are multilingualism, migration, and history teaching-contexts where intercultural dialogue is most often discussed in our data-but also lifelong learning. The themes are linked in various ways.

A few longer excerpts taken from some of the documents show a high co-occurrence rate of concepts examined in our research. The conceptual densities in these excerpts illustrate how the meanings of intercultural dialogue are constructed in our data. In other words, in the passages where different concepts related to intercultural dialogue occur together, the 
semantic web becomes especially rich. We now illustrate this richness by looking at excerpts related to each of the four themes in turn.

\section{Intercultural Dialogue in the Context of Multilingualism}

Our first longer excerpt is from the European Commission's 2005 communication, the New Framework Strategy for Multilingualism. This document aims to complement the Commission's "current initiative to improve communication between European citizens and the institutions that serve them" (CofEC 2005, 2). Moreover it "reaffirms the Commission's commitment to multilingualism in the European Union; sets out the Commission's strategy for promoting multilingualism in European society, in the economy and in the Commission itself; and proposes a number of specific actions stemming from this strategic framework" (ibid.). The document does not explicitly use the concept of intercultural dialogue but refers to "interculturalism" and "intercultural communication skills" (CofEC 2005, 6, 8-9, 20). It can, however, be interpreted as implicitly addressing intercultural dialogue through utilizing concepts, terms, and expressions typically used for discussing ideas, policy goals, and practices of intercultural dialogue.

The introductory section of the document introduces its core conceptual framework by starting from "European values" and how they are related to diversity. In this section, diversity is explicitly described as covering core anthropological differences (except ethnicity) between people: cultures, customs, beliefs, and languages. As the title indicates, the first subsection of the introduction sets out certain values as European. All these values are based on the idea of respect for different kinds of diversities. This respect is simultaneously understood as the foundation and source of mutual understanding and "unity in diversity" in the European Union (ibid., 2-3). The next excerpt illustrates the manner in which various concepts, terms, and expressions intertwine in the discourse that addresses multilingualism in the context of European values:

\section{I.1 Multilingualism and European Values}

The European Union is founded on 'unity in diversity': diversity of cultures, customs and beliefs-and of languages. Besides the 201 official languages of the Union, there are 60 or so other indigenous languages and scores of non-indigenous languages spoken by migrant communities. 
It is this diversity that makes the European Union what it is: not a 'melting pot' in which differences are rendered down, but a common home in which diversity is celebrated, and where our many mother tongues are a source of wealth and a bridge to greater solidarity and mutual understanding.

Language is the most direct expression of culture; it is what makes us human and what gives each of us a sense of identity. Article 22 of the Charter of Fundamental Rights of the European Union states that the Union shall respect cultural, religious and linguistic diversity. Article 21 prohibits discrimination based on a number of grounds, including language. Together with respect for the individual, openness towards other cultures, tolerance and acceptance of others, respect for linguistic diversity is a core value of the European Union. Action by the Union and the Member States to uphold multilingualism therefore has a direct impact on the life of every citizen. (CofEC 2005, 2, footnotes removed, emphasis added)

As becomes clear from this quote (and our emphases added to it), the discourse in the document includes a thick web of conceptual overlaps and interrelations. Semantic overlaps include diversity, culture, and languages (both indigenous and non-indigenous); wealth, solidarity, and mutual understanding; identity and cultural, religious, and linguistic diversity; and respect, openness, tolerance, multilingualism, and citizen(ship). Here, language is acknowledged as a building block of both European and individual identity and as an expression of culture. Linguistic diversity is equated with cultural and religious diversity as a celebrated and respected feature and core value of the European Union. Moreover, openness towards other cultures and respect for linguistic diversity imply that intercultural dialogue is inherent in the concept of multilingualism. This reflects the Council of Europe's White Paper (CofE 2008b, 10-11) in which intercultural dialogue is defined as resting upon an "open and respectful exchange of views between individuals, groups with different ethnic, cultural, religious and linguistic backgrounds and heritage on the basis of mutual understanding and respect".

This document emphasizes how language is an important issue to consider when aiming at facilitating intercultural dialogue or, in the words of the Commission, "solidarity and mutual understanding" within the European Union. In order to establish this understanding, skills or competences are needed to help people interact. There is a broad body of literature on intercultural competence, what it means, and how it could be 
obtained (Spitzberg and Changnon 2009; Barrett 2013a). Typically, the different takes on this emphasize adaptability in culturally diverse situations and sensitivity in interaction with people (or in dealing with representations of people) who are different from ourselves (see Barrett 2013a, 148-149). Barrett (2013a, 152) defines intercultural competence as "the set of values, attitudes, knowledge, understanding, skills and behaviours which are needed for: understanding and respecting people who are perceived to be cultural different from oneself; interacting and communicating effectively and appropriately with such people; and establishing positive and constructive relationships with such people". Language skills are essential in establishing intercultural competence.

The Council of Europe's White Paper on Intercultural Dialogue, the seminal paper of European intercultural dialogue policies, allegedly does not address the issue of language in detail. In fact, language is a somewhat neglected theme in the document. As Méndez García and Byram (2013, 133 ff) note, the White Paper avoids discussing how and in which language(s) the dialogues it envisions are going to take place. The White Paper does note that language is often "a barrier to conducting intercultural conversations" (CofE 2008b, 29), but it does not develop this concern in depth. As a general term, language may refer to official languages, minority languages, mother tongue, foreign and additional languages, and migrant languages - or, as the earlier-cited excerpt illustrates, indigenous and non-indigenous languages. The language barrier is also addressed by Barrett $(2013 \mathrm{~b}, 27)$, who notes that, besides individuals, groups, and political organizations "preaching hatred and intolerance towards people with different cultural affiliations", the difficulty of communicating without a lingua franca is one of the potential barriers to successful intercultural dialogue.

Ability to communicate in different languages has been explained and theorized with several concepts, such as multilingualism and plurilingualism. These concepts have been discussed in academia in the context of cultural diversity. According to Méndez García and Byram, the duality between multilingualism and plurilingualism is different from the dichotomy of interculturalism and multiculturalism. While multilingualism (understood as coexistence of several languages) is commonly related to multiculturalism (understood as coexistence of several cultural communities), such an obvious link does not exist between plurilingualism and interculturalism. The difference between the latter two lies in the process of identification. Someone who is plurilingual identifies with more than 
one language and more than one culture. In turn, interculturalism, or "interculturality" in Méndez García and Byram's discussion, encompasses "the capacity to experience and analyze cultural otherness, and to use this experience to reflect on matters that are usually taken for granted within one's own culture and environment" (Byram et al. 2009, 6; Méndez García and Byram 2013, 141, emphasis added). Interculturalism or intercultural dialogue does not expect identification with several cultures.

In the New Framework Strategy for Multilingualism, multilingualism is defined both as a person's ability and as a feature of diversity within a locality:

Multilingualism refers to both a person's ability to use several languages and the co-existence of different language communities in one geographical area. In this document, the term is used to describe the new field of Commission policy that promotes a climate that is conducive to the full expression of all languages, in which the teaching and learning of a variety of languages can flourish. (CofEC 2005, 3)

In general, language issues are commonly addressed in our data, also in the documents by the Council of Europe. One of its early documents, the European Cultural Convention (CofE 1954) speaks of the cultural exchange needed in order for the peoples of the member states to study each other's languages, histories, and civilizations. Within the Council of Europe documents, language issues are present above all in relation to schooling equality and migration. Regarding schooling equality, they focus on the national languages of the member states and the official languages of the Council of Europe (defined as English and French in CofE $2015,140,181,183$ ), as well as non-discrimination based on language, alongside race, ethnic or social origin, disability, religion, gender, political opinion, and so forth (CofE 1997, 5). Language issues feature prominently in the context of immigration, seen as early as the European Cultural Convention (CofE 1954). These issues include validating migrants' skills (CofE 2011a), improving migrants' employment (CofE 2008c), or advancing migrants' legal status in general (CofE 1977). The Council of Europe's document on children and adolescents from a migrant background (CofE 2018) points towards "language policy guidelines" and the Language Policy Programme (Language Policy Portal: www.coe. int/lang), and it notes that in order for people of migrant origin to integrate in the country in which they live and access schooling, they should 
"understand, speak and read that country's language" (CofE 2018, $2,6,29)$.

Besides this, member states should also "promote and facilitate, as far as practicable, the teaching of the migrant worker's mother tongue to the children of the migrant worker" (CofE 2018, 5) because mother tongues are seen "both as educational and cultural instruments" which "maintain and improve" the immigrants (and their children's) "links with their culture of origin" (CofE 2018,7). The same document quotes the Council of Europe's recommendation concerning modern languages, on the necessity to ensure that "there is parity of esteem between all the languages and cultures" in bilingual or multicultural areas so that "children in each community may have the opportunity to develop oracy and literacy in the language of their own community as well as to learn to understand and appreciate the language and culture of the other" (CofE 2018, 8-9). Similarly, the Council of the European Union's conclusions on the education of children with a migrant background stress that these children need to maintain a link to their "heritage culture and language" (CofEU 2009, 3, 7). The policies dealing with language and migration are mainly concerned with migrants' language skills-whether this means learning their host countries' languages or to maintaining their mother tongues.

Intercultural dialogue and human interaction rest on the ability to understand one's interlocutor(s). Though language is often approached in our data from this practical point of view, it also given deeper cultural meanings related to identities, heritages, and empathic encounter of other people. This meaning is also highlighted in the Commission's 2008 communication on multilingualism: "Languages define personal identities, but are also part of a shared inheritance. They can serve as a bridge to other people and open access to other countries and cultures, promoting mutual understanding" (CofEC 2008b, 3). Furthermore, multilingualism - and intercultural dialogue as belonging to it - is considered advantageous in a globalized world, as it is argued that "a successful multilingual policy can strengthen life chances of citizens: it may increase their employability, facilitate access to services and rights and contribute to solidarity through enhanced intercultural dialogue and social cohesion" (CofEC 2008b, 3). 


\section{Intercultural Dialogue in the Context of Migration}

As is evident from the previous chapter, the Council of Europe's 2018 recommendation on integrating and educating young people from a migrant background constructs intercultural dialogue through dense clusters of concepts, terms, and expressions. The document, a compilation of extracts from various conventions, recommendations, resolutions, and reports, was created by the Language Policy Programme of the Education Policy Division at the Council of Europe. It seeks to "set out the principles governing actions in the migration field" and-as noted earlier-offers "language policy guidelines and reference tools developed to support their effective implementation in member states" so as to achieve "an inclusive approach based on shared values and principles" (CofE 2018, 2). The guiding prescript of the document points out that further issues related to the document are discussed on the "[p]latform of resources and references for plurilingual and intercultural education" (ibid.), which explicitly links the document to the concept of plurilingualism and interculturalism in education.

Some of the densest conceptual references to intercultural dialogue can be found in this document's recommendation on teacher training in education for intercultural understanding, notably in the context of migration. This recommendation originally dates back to 1984, and to better suit the thematic focus of the compilation document, its authors shortened it as follows:

The Committee of Ministers, $[\ldots]$

[...]

6. Considering that flourishing relations in all fields require a fuller understanding of the cultures and ways of life of other peoples as well as, in the event of their common cultural heritage;

7. Considering that the presence in schools in Europe of millions of children from foreign cultural communities constitutes a source of enrichment and a major medium- and long-term asset, provided that education policies are geared to fostering open-mindedness and an understanding of cultural differences;

8. Considering the essential role of teachers in helping such pupils to integrate into school and society, as well as in developing mutual understanding;

$[\ldots]$ 
10. Considering that, in order to fulfil this task, the training given to teachers should equip them to adopt an intercultural approach and be based on an awareness of the enrichment constituted by intercultural understanding and of the value and originality of each culture;

$[\ldots]$

12. Considering, too, that teachers issuing from migrant populations are particularly suited to creating with their pupils an educational process which takes account of the interaction of the features of their cultures of origin and of their host milieu;

I. Recommends:

A. that the governments of member states $[\ldots]$

1. make the intercultural dimension and the understanding between different communities a feature of initial and in-service teacher training, and in particular:

1.l train teachers in such a way that they:

- become aware of the various forms of cultural expression present in their own national cultures, and in migrant communities;

- recognise that ethnocentric attitudes and stereotyping can damage individuals, and therefore, make an attempt to counteract their influence

- realise that they too should become agents of a process of cultural exchange and develop and use strategies for approaching, understanding and giving due consideration to other cultures as well as educating their pupils to give due consideration to them;

$[\ldots]$

2. encourage the development and use of appropriate materials to support the intercultural approach in the training of teachers and in school in order to give a "truer" image of the different cultures of their pupils;

$[\ldots]$

4. where appropriate, encourage the holding of national and international seminars and courses on the intercultural approach to education for teachers, teacher trainers, administrators and other persons involved in teacher-training, including welfare and labour officers who have close professional relations with migrant families. (CofE 2018, 7-8, emphasis added, omitted passages in the original)

In this excerpt, the five underlying considerations-which present migration as a source of enrichment, an asset, and a valued source of cultural diversity within the European community - are followed by a recommendation to make intercultural considerations an initial and in-service 
feature of teacher training. The recommendation also states that education policies in general be "geared to fostering open-mindedness and an understanding of cultural differences" in a manner that promotes integration and mutual understanding. The 'intercultural' is, thus, presented as a valuable feature of Europe to be promoted on the policy level in educational models that encompass teacher education, using appropriate materials for an "intercultural approach". The document also recommends arranging national and international seminars to combat ethnocentrism and false images of cultural others. "Awareness" of cultural differences and their value is an expression that comes up repeatedly in our data and can be linked to the idea of intercultural competence or skill alongside "open-mindedness" and "understanding of cultural differences". Here, "recognition", "due consideration", and "encouragement" of appropriate attitudes, materials, and educational means, as well as cultural differences in general, are depicted as tools of intercultural training.

As the policy context of this excerpt focuses on migration and teacher education, it presents migration in a cultural, rather than economic, light. The concepts related to intercultural dialogue that overlap in this case are cultures, cultural heritage, and cultural expression-all bound up with positive value statements. Explicit references to the 'intercultural' appear in the text as attached to the words "understanding", "dimension", "feature of teacher training", and "approach". Positive value statements are signalled by the use of wording such as "flourishing relations", "source of enrichment", and "a major medium- and long-term asset", as well as plain "value". Negative value is attached to ethnocentrism and stereotyping, which are described as possibly damaging to individuals. The positive and negative value statements are further discussed in the next chapter dealing with affectively sticky concepts. Besides teachers, welfare and labour officers dealing with migrants are mentioned among the professionals that need to engage in or profit from intercultural education. It is also worth noting that teachers of migrant background are mentioned as especially suited to creating intercultural education processes with their pupils. Above all, intercultural education is presented here as a form of awareness raising in the context of migration.

Though migration is a common context of intercultural education in the European education policy documents, immigrants are also referred to in other contexts in our data. Policy discourses seeking to advance immigrants' inclusion and integration in European societies also emphasize issues of employment and the economy. In general, the promotion of 
intercultural dialogue in our data stems from and combines economic, societal, educational, social, cultural, and historical contexts. The social and historical contexts are apparent in the discussion of intercultural dialogue in history teaching that follows.

\section{Intercultural Dialogue in the Context of History Teaching}

Calls for dialogical approaches to history teaching are made in statements such as the Council of Europe's 2001 recommendation on the future of history teaching in Europe, which states that:

History teaching in a democratic Europe should [-] make it possible to develop in pupils the intellectual ability to analyse and interpret information critically and responsibly, through dialogue, through the search for historical evidence and through open debate based on multiperspectivity, especially on controversial and sensitive issues. (CofE 2001, 4)

In the context of history teaching, the densities of significant concepts related to ideas and practices of intercultural dialogue follow the same value-laden rhetoric as in the cases of multilingualism and migration. These densities tend to cluster around value statements that celebrate cultural diversity, or, as in the aforementioned quote, multiperspectivity. The Council of Europe's 2011 recommendation on intercultural dialogue in history teaching describes cultural diversity as "great" and a "shared asset" and calls for "increasing sensibility to the diverse cultural legacies" of present-day European societies. According to this document, this sensibility may be fostered via knowledge of the "cultural history of the world's other regions and civilisations" (CofE 2011b, 4), as well as through placing one's own local, regional, and national history in a wider, global context. The recommendations begin by describing the aims of history teaching:

Goals of history teaching in the context of intercultural dialogue

With a view to strengthening intercultural dialogue, and having regard to the general aims of history teaching as embodied in Recommendation $\operatorname{Rec}(2001) 15$, history teaching should contribute in particular to: 
- raising awareness regarding the great cultural diversity of presentday European societies, and to increasing sensibility to the diverse cultural legacies of those societies;

- better knowledge, in the general context of globalisation, of the cultural history of the world's other regions and civilisations while maintaining an appropriate focus on local, national and regional history;

- positioning national culture and history in the European context and to positioning European culture and history in the world perspective;

- knowledge about the history of the relationships between cultures, civilisations and peoples, and about the contribution of each to the development, growth and creativity of the others;

- the development of the knowledge and skills needed to establish open, productive intercultural dialogue by enabling all future citizens to gain a perception and understanding of the history of others, and thereby better to perceive and understand their own;

- the development of a multiple-perspective approach in the analysis of history, especially the history of the relationships between cultures;

- the pinpointing and critical analysis of stereotypes, cut-and-dried images, bias, old-fashioned views and interpretations that are improper or liable to breed real misunderstandings or, more generally, inappropriate images of others;

- the prevention of tension and conflict in sensitive situations and to the furtherance of reconciliation processes in conflict and postconflict situations, above all where cultural diversity in the broad sense is or has been exploited in conflicts of a political kind;

- in association with other disciplines, fostering the preconditions for productive intercultural dialogue, namely promotion of the common values and references such as the fundamental rights needed for dialogue to be established on a sound basis, as specified in the White Paper;

- enabling future citizens to give their fully informed consent to "live together" in complex, changing contexts whose developments are often unpredictable or unexpected. (CofE 2011b, 4-5, emphasis added)

In this excerpt, intercultural dialogue is framed through various concepts, terms, and expressions already discussed in relation to previous examples. The excerpt emphasizes cultural diversity and relationships between different cultures and seeks to raise "awareness" and "sensibility" towards the difference. Though the text addresses knowledge about the 
relationship of cultures and "the contribution of each to the development, growth and creativity of the others", it still draws a clear distinction between one's own culture and history and those of others. The text deals with culture and history only in territorial terms and as concentrated circles-local, regional, national, and European-as distinct from culture and history elsewhere, that is, the "cultural history of the world's other regions and civilisations". The excerpt includes value rhetoric referring to "common values and references, such as fundamental rights" as the basis for intercultural dialogue.

The document provides a specified list of skills, abilities, and attitudes through which it recommends advancing "the learning of the history of others" (CofE $201 \mathrm{lb}, 8$, title). The listed attitudes include interest, curiosity, awareness, and receptiveness. The list includes the abilities "to perceive cultural diversity as a shared asset"; "to position one's own culture in a broader context"; "to identify stereotypes and prejudices"; "to hear and respect other viewpoints and be amenable to dialogue"; "to control one's emotions and accept when other people express theirs"; "to distinguish what pertains to the facts of history from judgments"; "to construct reasoned critical judgments"; and "to comprehend, compare and analyse sources of different kinds and origins" (CofE 2011b, 8-9). Awareness raising is, again, mentioned as one of the most valuable goals of teaching intercultural dialogue, while knowledge is connected to critical analysis as the means to the desired multi-perspective end.

In the discourse of the recommendation, the ultimate aim of history teaching in the context of intercultural dialogue is to battle old-fashioned views and improper interpretations or stereotypes that breed misunderstandings and inappropriate images of others in ways that may lead to tension and conflicts. Although it is not mentioned explicitly, the goal of this kind of history teaching is to prevent the recurrence of the conflicts that continue to define the key themes in European history writing.

\section{Intercultural Dialogue in the Context OF LIFELONG LEARNING}

The process of acquiring and maintaining one's competence in intercultural dialogue may be regarded as lifelong learning. The origins of the idea of lifelong learning can be traced back to the 1960s and 1970s, but interest in the subject really peaked in the 1990s. By the beginning of the twenty-first century, the concept had been adopted "with an astonishing political consensus in the postindustrial societies of the western 
hemisphere", as Siivonen $(2010,38)$ notes. The reasons behind this embrace of lifelong learning as a political concept can be sought in the 'new economy' with its move from manufacturing to services and innovative business design, and its increasing demand for an ever-flexible workforce (Siivonen 2010, 38-39). The firm belief in education as the promoter of societal progress - the core idea included in lifelong learning (Siivonen 2010,39)-is prevalent in European education policies.

In its White Paper on Intercultural Dialogue, the Council of Europe argues that intercultural competence needs to be "learned, practised and maintained throughout life" (CofE 2008b, 29). Formal education (primary, secondary, and higher education) systems are the core promoters of intercultural competence, but civil society organizations, religious communities, and the media make an important contribution to developing intercultural competence (CofE 2008b, 29; Barrett 2013b, 26-27). The idea of acquiring and maintaining intercultural competence throughout one's life also is emphasized by the European Parliament and the Council of the European Union in their 2006 recommendation on the key competences for lifelong learning. This document recommends that member states "develop the provision of key competences for all as part of their lifelong learning strategies, including their strategies for achieving universal literacy, and use the 'Key Competences for Lifelong Learning-A European Reference Framework' [-] as a reference tool" (EP \& CofEU 2006, 11). This framework introduces eight key competences: communication in the mother tongue; communication in foreign languages; mathematical competence and basic competences in science and technology; digital competence; learning to learn; social and civic competences; sense of initiative and entrepreneurship; and cultural awareness and expression. Though intercultural dialogue is not mentioned in the document as such, the descriptions of "communication in foreign languages" and "social and civic competences" implicitly evoke it by referring to "intercultural understanding" (ibid., 14), "intercultural communication" (ibid., 15, 17), and "intercultural competences" (ibid., 16). Here, the 'intercultural' is again related to "appreciation of cultural diversity" (ibid., 15) and respecting others. The document's definition of social competence includes a density of concepts, terms, and expressions that are commonly used in discussing intercultural competence:

Social competence is linked to personal and social well-being which requires an understanding of how individuals can ensure optimum physical and mental health, including as a resource for oneself and one's family and one's 
immediate social environment, and knowledge of how a healthy lifestyle can contribute to this. For successful interpersonal and social participation it is essential to understand the codes of conduct and manners generally accepted in different societies and environments (e.g. at work). It is equally important to be aware of basic concepts relating to individuals, groups, work organisations, gender equality and non-discrimination, society and culture. Understanding the multi-cultural and socio-economic dimensions of European societies and how national cultural identity interacts with the European identity is essential.

The core skills of this competence include the ability to communicate constructively in different environments, to show tolerance, express and understand different viewpoints, to negotiate with the ability to create confidence, and to feel empathy. Individuals should be capable of coping with stress and frustration and expressing them in a constructive way and should also distinguish between the personal and professional spheres.

The competence is based on an attitude of collaboration, assertiveness and integrity. Individuals should have an interest in socio-economic developments and intercultural communication and should value diversity and respect others, and be prepared both to overcome prejudices and to compromise. (EP \& CofEU 2006, 17, emphasis added)

As the excerpt illustrates, intercultural competence is approached and embedded in a broader framework of social competence. The description of this competence ties together concepts such as social participation, culture, gender equality, non-discrimination, identity, tolerance, empathy, diversity, and respect.

Skills relevant for intercultural dialogue are also inherent in the definition of cultural awareness and expression:

A solid understanding of one's own culture and a sense of identity can be the basis for an open attitude towards and respect for diversity of cultural expression. A positive attitude also covers creativity, and the willingness to cultivate aesthetic capacity through artistic self-expression and participation in cultural life. (Ibid., 18, emphasis added)

Here, intercultural dialogue is evoked through openness and respect for diversity, and connected to "[a] solid understanding of one's own culture a sense of identity" and "participation in cultural life" (ibid.). Intercultural dialogue, thus, comes across as an important skill on both the social and societal levels. 


\section{Intercultural Dialogue as a Key Skill In Europe Today}

The dense occurrences of concepts analysed in this chapter illustrate how intercultural dialogue is discussed in the European education policy documents through the use of varied related concepts that bring with them a multitude of meanings. Our research on these dense occurrences indicates how the ability to practise intercultural dialogue can be seen as one of the most important transversal skills for Europeans today, in a globalized world that increasingly requires communication between cultures. Yet, as recently as 2017, the European Commission still remarked that there is a "mismatch" between the skills that Europe needs and the skills that it has.

The European Commission's recent Renewed EU Agenda for Higher Education calls for improvement in both basic literacy, numeracy, and digital skills acquired during compulsory schooling and transversal skills such as problem-solving and communication (EC 2017a, 3). The Commission's communication on School Development and Excellent Teaching for a Great Start in Life from the same year likewise calls for transversal skills such as creativity and critical thinking (EC 2017b, 3, 5). From our point of view, competence for intercultural dialogue represents exactly this kind of transversal and ever-timely competence, which all age groups need in a range of situations. Thus, intercultural dialogue should be explicitly promoted in education policies.

\section{REFERENCES}

Barrett, M. 2013a. Intercultural Competence: A Distinctive Hallmark of Interculturalism? In Interculturalism and Multiculturalism: Similarities and Differences, ed. M. Barrett, 147-168. Strasbourg: Council of Europe.

- 2013b. Introduction-Interculturalism and Multiculturalism: Concepts and Controversies. In Interculturalism and Multiculturalism: Similarities and Differences, ed. M. Barrett, 15-42. Strasbourg: Council of Europe.

Byram, M., M. Barrett, J. Ipgrave, R. Jackson, and M.C. Méndez García. 2009. Autobiography of Intercultural Encounters: Context, Concepts and Theories. Strasbourg: Council of European Publishing.

CofE (Council of Europe). 1977. European Convention on the Legal Status of Migrant Workers. Strasbourg, 24 November 1977. Strasbourg: Council of Europe. 
1997. The Lisbon Convention (Convention on the Recognition of Qualifications concerning Higher Education in the European Region). Lisbon, 11 April 1997. Strasbourg: Council of Europe.

- 1954. European Cultural Convention. Paris, December 19. Strasbourg: Council of Europe.

- 2001. Recommendation Rec(2001)15 on History Teaching in Twenty-FirstCentury Europe. Adopted by the Committee of Ministers on 31 October 2001 at the 771st Meeting of the Ministers' Deputies. Strasbourg: Council of Europe.

- 2008a. Recommendation Rec(2008)4 on Strengthening the Integration of Children of Migrants and of Immigrant Background. Adopted by the Committee of Ministers on 20 February 2008 at the 7018th Meeting of the Ministers' Deputies. Strasbourg: Council of Europe.

- 2008b. White Paper on Intercultural Dialogue. In Living Together as Equals in Dignity. Strasbourg: Council of Europe.

- 2008c. Recommendation Rec(2008)10 on Improving Access of Migrants and Persons of Immigrant Background to Employment. Adopted by the Committee of Ministers on 10 July 2008 at the 7032nd Meeting of the Ministers' Deputies. Strasbourg: Council of Europe.

- 2011a. Recommendation Rec(2011)2 on Validating Migrants' Skills. Adopted by the Committee of Ministers on 19 January 2011 at the 1103rd Meeting of the Ministers' Deputies. Strasbourg: Council of Europe.

- 2011b. Recommendation Rec(2011)6 on Intercultural Dialogue and the Image of the Other in History Teaching. Adopted by the Committee of Ministers on 6 July 2011 at the 1118th Meeting of the Ministers' Deputies. Strasbourg: Council of Europe.

- 2015. European Social Charter (Collected Texts, 7th Edition). I January 2015. Strasbourg: Council of Europe.

- 2018. Children and Adolescents from a Migrant Background: Integration and Education. Extracts from Conventions, Recommendations, Resolutions and Reports. Revised and Enriched Version-April 2018. Strasbourg: Council of Europe.

CofEC (Commission of the European Communities). 2005. Communication from the Commission to the Council, the European Parliament, the European Economic and Social Committee and the Committee of the Regions. $\operatorname{COM}(2005)$ 596 Final. A New Framework Strategy for Multilingualism. Brussels: Commission of the European Communities.

- 2008a. Communication from the Commission to the European Parliament, the Council, the European Economic and Social Committee and the Committee of the Regions. Improving Competences for the 21st Century: An Agenda for European Cooperation on Schools. COM(2008) 425 Final. Brussels: Commission of the European Communities. 
2008b. Communication from the Commission to the European Parliament, the Council, the European Economic and Social Committee and the Committee of the Regions-Multilingualism: An Asset for Europe and a Shared Commitment. $\operatorname{COM}(2008) 566$ Final. Brussels: Commission of the European Communities. CofEU (Council of the European Union). 2009. Council Conclusions of 26 November 2009 on the Education of Children with a Migrant Background, 2009/C 301/07. Official Journal of the European Union C301: 5-8.

- 2013. 2013/776/EU: Commission Implementing Decision of 18 December 2013 Establishing the 'Education, Audiovisual and Culture Executive Agency' and Repealing Decision 2009/336/EC. Official Journal of the European Union L343: 46-53.

CofEU \& EC (Council of the European Union \& the European Commission). 2015. Joint Report of the Council and the Commission on the implementation of the Strategic Framework for European Cooperation in Education and Training (ET 2020): New Priorities for European Cooperation in Education and Training. (2015/C 417/04). Official Journal of the European Union C417: 25-35.

EC (European Commission). 2017a. Communication from the Commission to the European Parliament, the Council, the European Economic and Social Committee and the Committee of the Regions on a Renewed EU Agenda for Higher Education. $\operatorname{COM}(2017) 247$ Final. Brussels: European Commission.

- 2017b. Communication from the Commission to the European Parliament, the Council, the European Economic and Social Committee and the Committee of the Regions: School Development and Excellent Teaching for a Great Start in Life. $\operatorname{COM}(2017) 248$ Final. Brussels: European Commission.

EP \& CofEU (European Parliament and the Council of European Union). 2013. Regulation (EU) no 1288/2013 of the European Parliament and of the Council of 11 December 2013 Establishing 'Erasmust': The Union Programme for Education, Training, Youth and Sport and Repealing Decisions No 1719/2006/EC, No 1720/2006/EC and No 1298/2008/EC (Text with EEA Relevance). Official Journal of the European Union L347: 50-73.

EP \& CofEU (European Parliament and the Council of the European Union). 2006. Recommendation of the European Parliament and of the Council of 18 December 2006 on Key Competences for Lifelong Learning. (2006/962/ EC). Official Journal of the European Union L394: 10-18.

Méndez García, M.C., and M. Byram. 2013. Interculturalism, Multiculturalism and Language Issues and Policies. In Interculturalism and Multiculturalism: Similarities and Differences, ed. M. Barrett, 133-146. Strasbourg: Council of Europe.

Siivonen, P. 2010. From a "Student" to a Lifelong "Consumer" of Education? Constructions of Educability in Adult Student's Narrative Life Histories. Jyväskylä: Finnish Educational Research Association. 
Spitzberg, B.H., and G. Changnon. 2009. Conceptualizing Intercultural Competence. In The SAGE Handbook of Intercultural Competence, ed. D.K. Deardorff, 2-52. Thousand Oaks: Sage.

Open Access This chapter is licensed under the terms of the Creative Commons Attribution 4.0 International License (http://creativecommons.org/licenses/ by $/ 4.0 /)$, which permits use, sharing, adaptation, distribution and reproduction in any medium or format, as long as you give appropriate credit to the original author(s) and the source, provide a link to the Creative Commons licence and indicate if changes were made.

The images or other third party material in this chapter are included in the chapter's Creative Commons licence, unless indicated otherwise in a credit line to the material. If material is not included in the chapter's Creative Commons licence and your intended use is not permitted by statutory regulation or exceeds the permitted use, you will need to obtain permission directly from the copyright holder.

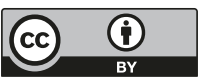

